\title{
Determination the optimal tilt and azimuth angle of photovoltaic system for maximum energy in Bucharest region, Romania - Case Study
}

\author{
Mihaela Andreea Mitiu ${ }^{1}$, Marius Viorel Olteanu ${ }^{1}$,Gyorgy Deak ${ }^{1}$, Natalia Simona Raischi ${ }^{1}$, and Danut Cociorva ${ }^{1}$ \\ ${ }^{1}$ National Institute for Research and Development in Environmental Protection - INCDPM Bucharest, 294, Spl. Independentei, \\ District 6th, Bucharest, Postal Code 060031, Romania
}

\begin{abstract}
This study was conducted to evaluate the feasibility of installing a photovoltaic system for supplying the electric load of an environmental institute and to determinate the optimal tilt and azimuth angle of an $100 \mathrm{~kW}$ photovoltaic power plant located on the roof of institute. Those parameters plays an important role in maximizing the solar radiation collected by a PV panel. Simulations were made with PVsyst V6.39 for south-east orientation $(100 ; 450)$ and south-west orientation $(100 ; 450)$, and for the tilt angle the simulations were made at 100,150,370,600 and 900. The simulation has been done to study the influence of the photovoltaic panels orientation on the amount of electricity produced each month of the year as well as on the total annual amount of electricity. Was experimentally determined by repetitive simulations in the range 300-400 for tilt angle and zero azimuth, optimal parameters for the position of photovoltaic panels. Was defined as the optimal position, the pair of values [zero azimuth, tilt angle 370] where the plant generates maximum energy in one year compared to any other set of values that defines the position of the photovoltaic panels.
\end{abstract}

\section{Introduction}

With rapid economic growth and improvement in living standards, there has been a marked increase in energy use for many developed and developing countries[1,2]. Sunlight is by far the largest carbon-free source of energy on the planet. Photovoltaic energy production is becoming more and more applied, being one of the main green energies[3]. The environmental impact due to the emission of pollutants and the consumption of nonrenewable resources is increasing, therefore the rational use of resources is necessary and use more and more of viable alternative resources[4,5]. Fossil fuels like oil, coal or gas, are the main sources of energy worldwide and their use causes greenhouse gas emissions into the atmosphere, thereby contributing to global warming[6]. The solar energy is virtually inexhaustible, it is renewable and non-polluting. The production of solar energy by solar panels or other means of using solar energy is noise-free, unlike other methods of producing electricity.

The major and important issue is to improve the efficiency of the photovoltaic power plant, the tilt angle and azimuth angle play important role towards the efficiency of the plant $[7,8]$.Solar panels or PV arrays are most efficient, when they are perpendicular to the sun's rays. It is critical issue to select the both angle to improve the efficiency of a photovoltaic panel [9].The amount of solar radiation captured by a PV depends on the angle of inclination and the orientation angle of the panel. These two parameters are very important for both solar energy experts and designers[10]. The performance of the PV modules varies depending on the location and prevailing environmental conditions to which it is subjected[11]. Because the intensity of the radiation changes at each moment, it is obvious that the production of energy by the solar cells will also be changeable. To achieve the highest PV yield, the local environmental parameters must be taken into account[12].

Optimum tilt angle of photovoltaic panels for different areas of Romania was calculated, the results of the study show that the largest PV plants should be installed in Bucharest, other large PV plants should be built in Constanta, Craiova, Timisoara, Galati, Iasi, Cluj Napoca and Brasov[13].

\section{Materials and methods}

This energy from the photovoltaic power plant is used to save conventional energy resources. The $100 \mathrm{~kW}$ photovoltaic plant contains 400 photovoltaic panels of $1.6 \mathrm{~m} \times 1 \mathrm{~m}$, polycrystalline cells type and occupies an area of $667 \mathrm{~m}^{2}$.The geographic dates of the location for which the simulations were made are: Bucharest, Romania, latitude $44.5^{\circ} \mathrm{N}$, longitude $26.2^{\circ} \mathrm{E}$ and altitude $81 \mathrm{~m}$.At this location exist a weather station MeteoNorm 7.1 that provided annual meteorological weather values for the simulation program. Simulations were made using 
PVsyst V6.39 software, for south-east orientation $\left(10^{0}\right.$; $\left.45^{\circ}\right)$ and south-west orientation $\left(10^{0} ; 45^{\circ}\right)$, for the tilt angle the simulations were made at $10^{\circ}, 15^{\circ}, 37^{\circ}, 60^{\circ}$ and $90^{\circ}$. The software PVsystused in this paper for simulation is a package for the study, sizing and data analysis of complete PV systems. This software can simulate shading and possible energy losses due to shading of a PV. The results are in the form of a full report, specific graphs and tables.

In the table 1 are presented the monthly meteo values for the studied location provided from MeteoNorm 7.1 station and the figure 1 present the solar paths at Bucharest, latitude $44.5^{\circ} \mathrm{N}$, longitude $26.2^{\circ} \mathrm{E}$ and altitude $81 \mathrm{~m}$. The diagram from figure 1 show the path of the sun across sky from the summer to winter solstice.

Table 1 Monthly meteo Values

\begin{tabular}{|l|l|l|l|l|l|l|l|l|l|l|l|l|l|}
\hline & Ian. & Feb. & Mar. & Apr. & Mai & Iun. & Iul. & Aug. & Sep. & Oct. & Nov. & Dec. & An \\
\hline $\begin{array}{l}\text { Hor. global } \\
{\left[\mathrm{kWh} / \mathrm{m}^{2} . \mathrm{mth}\right]}\end{array}$ & 43.3 & 69.6 & 109.9 & 143.5 & 181.7 & 195.8 & 203.9 & 178.3 & 125.0 & 85.0 & 45.9 & 37.7 & 1415.6 \\
\hline $\begin{array}{l}\text { Hor. diffuse } \\
{\left[\mathrm{kWh} / \mathrm{m}^{2} . \mathrm{mth}\right]}\end{array}$ & 23.6 & 29.2 & 46.4 & 69.7 & 77.1 & 79.3 & 82.9 & 73.4 & 55.2 & 39.5 & 28.7 & 20.1 & 625.1 \\
\hline $\begin{array}{l}\text { Extraterrestrial } \\
{\left[\mathrm{kWh} / \mathrm{m}^{2} . \mathrm{mth}\right]}\end{array}$ & $\begin{array}{l}108 . \\
6\end{array}$ & 142.5 & 219.6 & 278.9 & 337.9 & 348.2 & 350.3 & 310.1 & 239.4 & 179.7 & 117.1 & 95.1 & 2728.4 \\
\hline Clearness Index & 0.39 & 0.489 & 0.500 & 0.511 & 0.538 & 0.562 & 0.582 & 0.575 & 0.522 & 0.473 & 0.389 & 0.365 & 0.519 \\
\hline Amb. Temper. $\left[{ }^{0} \mathrm{C}\right]$ & -1.0 & 1.5 & 6.7 & 11.8 & 17.9 & 21.1 & 23.7 & 23.4 & 17.1 & 11.9 & 6.4 & 0.4 & 11.7 \\
\hline Wind velocity $[\mathrm{m} / \mathrm{s}]$ & 2.8 & 2.9 & 3.1 & 3.0 & 2.6 & 2.5 & 2.4 & 2.3 & 2.4 & 2.3 & 2.6 & 2.8 & 2.6 \\
\hline
\end{tabular}

Source MeteoNorm 7.1 station

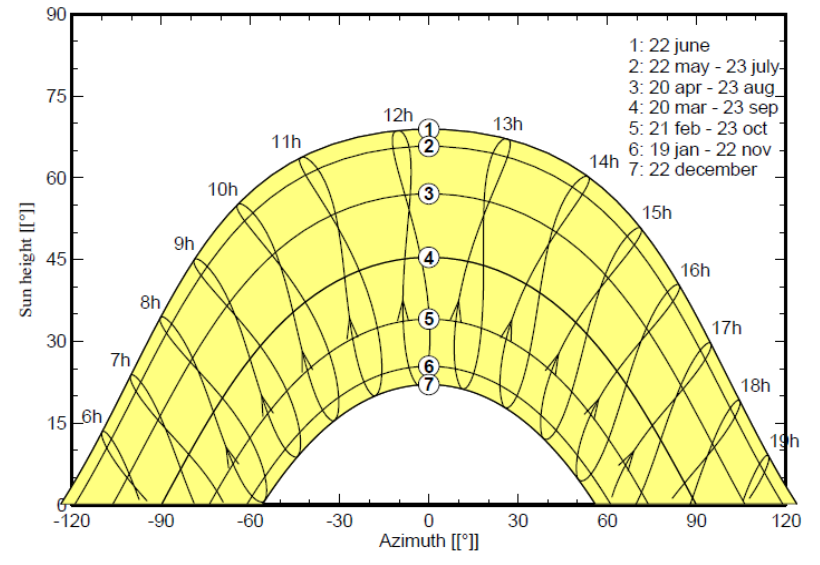

Fig.1 Solar paths at Bucharest (Lat. $44.5^{\circ} \mathrm{N}$, long. $26.2^{0} \mathrm{E}$. alt. $51 \mathrm{~m})$

To define the orientation of the photovoltaic panels, it is enough to consider two parameters: Azimuth representing the angle of the meridian intersecting the photovoltaic panel plane and the ZERO meridian plus the name of the cardinal point EST or WEST closest to the intersecting meridian. Thus, azimuth $=0$ means that the panel is oriented exactly to the SUD. The $10^{\circ}$ EST azimuth means the panel is ten degrees from the SUD to the EST. And the second parameter is Tilt Angle of the photovoltaic panels to the horizontal plane. This can vary from $0^{\circ}$, where photovoltaic panels are mounted horizontally up to $90^{\circ}$, panels mounted vertically.

\section{Results and discussions}

The simulation on $100 \mathrm{~kW}$ photovoltaic power plant located in Bucharest region, Romania has been done to study the influence of the orientation of photovoltaic panels on the amount of electricity produced each month of the year as well as on the total annual amount of electricity. Following the simulations was defined as the optimal position, the pair of values [zero azimuth, tilt angle 370] where the plant generates maximum energy in one year compared to any other set of values that defines the position of the photovoltaic panels. In the table 2 are presented the values obtaining after the simulation for the optimal position of the photovoltaic panels, these data show the energy produced by the 100 $\mathrm{kW}$ photovoltaic power plant every month of the year. For the optimal position result after simulation, the total amount of energy that is injected in to the grid for the entire year is $142983 \mathrm{~kW} \mathrm{~h}$.

Table 2. Dates obtaining for values zero azimuth, tilt angle 370 for the photovoltaic power plant

\begin{tabular}{|c|c|c|c|c|}
\hline & $\begin{array}{c}\text { Gl. Horiz. } \\
{\left[\mathrm{kWh} / \mathrm{m}^{2} . \text { day }\right.} \\
]\end{array}$ & $\begin{array}{c}\text { Coll.Plane } \\
{\left[\mathrm{kWh} / \mathrm{m}^{2} . \text { day }\right.} \\
]\end{array}$ & $\begin{array}{c}\text { System } \\
\text { output } \\
{[\mathrm{kWh} / \text { day }} \\
]\end{array}$ & $\begin{array}{c}\text { System } \\
\text { output } \\
{[\mathrm{kWh} / \mathrm{month}} \\
]\end{array}$ \\
\hline Jan. & 1.40 & 2.57 & 217.8 & 6753 \\
\hline Feb. & 2.49 & 4.12 & 349.9 & 9796 \\
\hline Mar. & 3.55 & 4.85 & 411.7 & 12764 \\
\hline Apr. & 4.75 & 5.35 & 454.2 & 13626 \\
\hline May & 5.86 & 5.87 & 498.1 & 15442 \\
\hline
\end{tabular}




\begin{tabular}{|c|c|c|c|c|}
\hline June & 6.53 & 6.16 & 523.0 & 15691 \\
\hline July & 6.58 & 6.34 & 538.5 & 16693 \\
\hline $\begin{array}{c}\text { Aug } \\
\text {. }\end{array}$ & 5.75 & 6.15 & 522.2 & 16187 \\
\hline Sep. & 4.17 & 5.21 & 442.6 & 13277 \\
\hline Oct. & 2.74 & 4.12 & 350.1 & 10853 \\
\hline $\begin{array}{c}\text { Nov } \\
\text {. }\end{array}$ & 1.53 & 2.50 & 212.2 & 6367 \\
\hline Dec. & 1.12 & 2.10 & 178.5 & 5534 \\
\hline $\begin{array}{c}\text { Yea } \\
\text { r }\end{array}$ & 3.88 & 4.61 & 391.7 & 142983 \\
\hline
\end{tabular}

In figure 2 are presented the evolution of the meteo and incident energy and system output after simulation, for the optimal position of the photovoltaic panels, the data are for the $100 \mathrm{~kW}$ photovoltaic power plant located in the area of Bucharest.

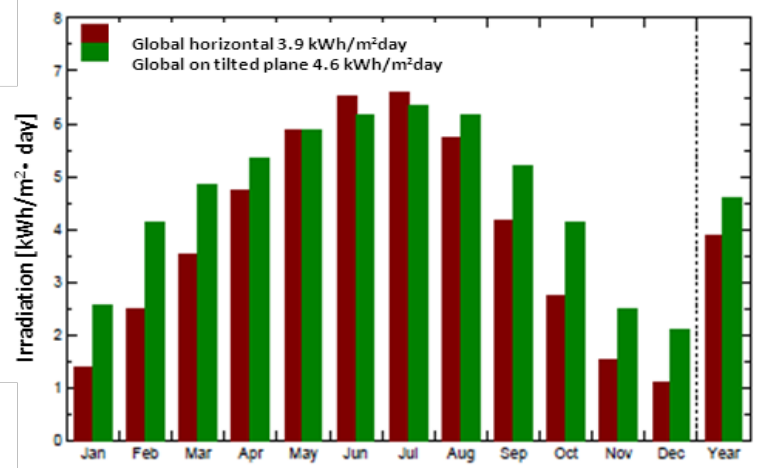

(a)

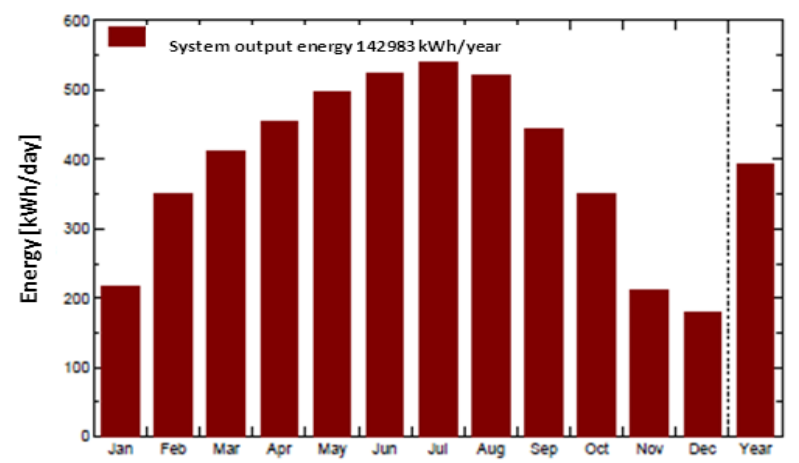

(b)

Fig.2 Meteo and incident energy (a) and system output(b), for the optimal position of the photovoltaic power plant

In July the $100 \mathrm{~kW}$ photovoltaic power plant generated the maximum energy, $16693 \mathrm{kWh}$ (a daily average of $538.5 \mathrm{kWh}$ ), ie $11.67 \%$ of the total energy produced in one year. The minimum energy generated by the power plant was in December, $5534 \mathrm{kWh}$, with a daily average of $134.3 \mathrm{kWh}$. This represents $33.15 \%$ of the energy produced in July and $3.87 \%$ of the total energy generated in one year (142983kWh).

In order to make it easier to observe the energy gain according to the inclination angle of the photovoltaic panels with respect to the horizontal plane, it can vary from $0^{0}$, where the photovoltaic panels are horizontally mounted, up to $90^{\circ}$, panels mounted vertically and South orientation, the energies were compared each month for each tilt, that is presented in the figure 3 .

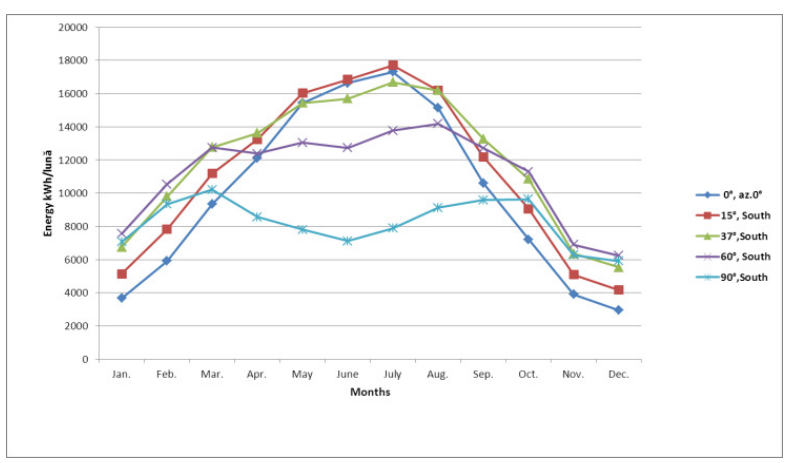

Fig.3 Monthly energy depending on tilt angle and south azimuth for the photovoltaic power plant located in the area of Bucharest

Curve $37^{0}$ - South from the figure 3 closes the largest surface / area. This means that the whole year's energy production is the highest and is therefore the optimal position. Compared with the position at $60^{\circ}$ where the latter has a higher production starting with the autumn equinox and up to the spring equinox, overall annual production is $6 \%$ lower at the $60^{\circ}$.In the case of vertically mounted ones, they have a higher production 15-20 days before and after the winter solstice, but throughout the year have a lower production by $31 \%$ than the optimal position of $37^{\circ}$.

Likewise, the panels mounted at $15^{0}$-South, from May until August, produce more energy than those mounted in the optimal position at $37^{\circ}$. But throughout the year, those inclined at $15^{0}$ have a $6 \%$ loss compared to the optimal inclination. However, if we look from the point of view of an investor on the Black Sea coast who wants to mount photovoltaic panels on the building, in the summer season he would have a higher gain with the $15^{\circ}$ inclination. For him the optimum is at $15^{0}$ where the consumption curve is higher in summer.

The energy values obtained (fig.4) for the same angle of inclination and azimuth were compared to see the optimal position where we have the highest energy gain.

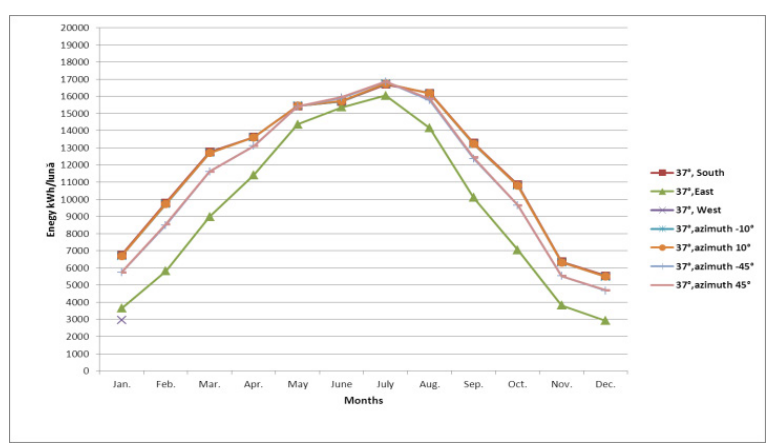


Fig.4 Monthly energy depending on different azimuth and the same tilt angle for the photovoltaic power plant located in the area of Bucharest

From figure 3 we can easily see how the curves at $37^{0}$ - azimuth $0^{0}, 37^{0}$-azimuth $+10^{0}, 37^{0}$-azimuth- $10^{\circ}$ are very close together, almost overlapping. This denotes that $\mathrm{a}+10^{0}$ deviation (even $+15^{0}$ ) does not affect the energy gain of the plant. At a deviation of $+45^{\circ}$, the loss already counts, and at $+90^{\circ}$ is significant. In the case when the roof has two plans, one to the East and the other to the West it will be mount half of the photovoltaic panels to the East and the other half to the West. In this way the losses are eliminated.

\section{Conclusions}

Following the simulations performed with the PVsyst V6.39 program, on $100 \mathrm{~kW}$ photovoltaic power plant, consisting of $400 \mathrm{PV}$, stretched over a surface of 667 $\mathrm{m}^{2}$, with dimensions $1.6 \mathrm{mx} 1 \mathrm{~m}$, of polycrystalline type, resulted in the following conclusions:

The optimal position of the photovoltaic panels regarding on the annual energy gain is the one at the $37^{0}$ tilt angle and the azimuth $0^{0}$. However, in this position, in the summer months, was not recorded the highest energy gain. On the total of the 12 months of the year is the position where the plant generates the largest amount of energy.

$A+10^{0}-15^{0}$ deviation from the optimal position (South orientation) does not greatly influence the energy gain. As shown by the values resulting from the simulation, the losses in this case are $0.3 \%$, insignificant. At $45^{0}$ the energy gain decreases by $5.5 \%$ compared to the optimal position.

The total East and West orientation reduces energy gain by $20.5 \%$ respectively $19.9 \%$, so we can consider a $20 \%$ loss in both cases. Panels mounted at $15^{\circ}$ South, starting with May until beginning of August, produce more energy than those mounted in the optimal position at $37^{\circ}$. But all year round, those inclined at $15^{\circ}$ have a loss of $6 \%$ compared to the optimal inclination.

At a deviation of $+45^{\circ}$ already the loss counts, and at $+90^{\circ}$ it is significant. If the roof has two plans, one to the East and the other to the West, will mount half of the photovoltaic panels to the East and the other half to the West. In this way, the losses are eliminated.

The research activities that underlie this article has been performed in a project which is part of Research Programe NUCLEU - contract 48N/2016 (PN 160402 01 ), financed by the Romanian Ministry of Research. The authors would like to thank the management and employees of the National Institute for Research \& Development in Environmental Protection for their valuable assistance and suggestions.

\section{References}

1. H.W. Li Danny and N. T. Lam Tony, International Journal of Photoenergy, 9 pages, (2007)

2. Mian Guo, Haixiang Zang, Shengyu Gao, Tingji Chen, Jing Xiao, Lexiang Cheng, Zhinong Wei 1 and Guoqiang Sun Appl. Sci.7,10, (2017)

3. Qingguo $\mathrm{Xu}$, Hongbo $\mathrm{Li}$, Guoqiang Hao, and Yefei Ding, JOCET 4, 6, (2016)

4. E. Holban, GY. Deák, V. Daescu, et al., JEPE 16, 2, 479-488, (2015)

5. GY. Deak, V. Daescu, E. Holban, et al., JEPE 16, 1, 304-315, (2015)

6. Ma J., Man K. L., Ting T. O., Zhang E. G., Guan S., Wong P. W., Krilavicius T., Sauleviius D., and Lei C. U., ktu, 20,1, 41-44, (2014)

7. Radhika, S.K. Suman (2015), IJAREEIE, 4 6, (2015)

8. M. Hartner, A. Ortner, A. Hiesl, R. Haas, Appl. Energ. 160, 94-107, (2015)

9. D. Jain, M. Lalwani, IJRER, 7, 3, 1053-1061, (2017)

10. K. Markam, K. Sudhakar, ITJET, 3, 5, 2735 2741, (2016)

11. E. B. Ettah, E. E. Eno, and A. B. Udoimuk, Journal of Association of Radiographers of Nigeria, 23, 16-22, (2009)

12. A. R. Gxasheka, E. E. van Dyk, and E. L. Meyer, Renewable Energy, 30, 4, 611-620, (2005)

13. V. Badescu, F. Iacobescu (2013), Energy for Sustainable Development 17, 220-227, (2013) 